\title{
Research on Counterattack Trip Rate Based on ATP-EMTP
}

\author{
J. Hao \& H.P. Zheng \& L.M. Bo \& X.J. Hao \& X.T. Cheng \\ Electric Power Research Institute, State Grid Shanxi Electric Power Company, Taiyuan, China \\ C. Zhang \\ State Grid Shanxi Electric Power Company, Taiyuan, Shanxi, China
}

\begin{abstract}
When the lightning trip accident happened on transmission line, the rate of counterattack trip is quite higher than shielding tripping. In this paper, the regulation method and ATP-EMTP simulation method are applied to analysis the result of counterattack trip rate in a practical $110 \mathrm{kV}$ network model. MATLAB is used for simulating in order to obtain the influence degree on counterattack tip rate affected by variables. According to the result, it is shown that: the prevention for lightning tripping on transmission line is supposed to concentrate on lightning counterattack and grounding resistance value of each tower whether meets the standard.
\end{abstract}

KEYWORD: lightning trip rate; ATP-EMTP; counterattack

\section{INTRODUCTION}

The transmission line tripped by lightning strike usually occurs in the line operation. The line is stroked by lightning is divided into two ways: strike and counterattack. Besides, the probability of tripping is closely related to lightning withstand level of tower. The approach to reduce the tripping frequency generally by lightning rod for decreasing the protection angle, while the tower suffered lightning shielding. Therefore, only the circumstance of counterattacking on the wire is considered when tower ground line suffered lightning (GAO Xin-zhi, et al., 2010; HUANG Wei-chao, et al., 2008; ZHENG Jiang, et al., 2009).

\section{CALCULATED COUNTER RATE OF TRANSMISSION LINE}

\subsection{Regulated Calculation}

According to DL620-1997, when the overhead line tower or ground line being stuck by lightning, the lightning protection level $\mathrm{I}$ is:

$$
\mathrm{I}=\mathrm{U}_{50 \%} /\left[\begin{array}{l}
(1-\mathrm{k}) \beta \mathrm{R}_{\mathrm{i}}+\left(\mathrm{h}_{\mathrm{a}} / \mathrm{h}_{\mathrm{t}}-\mathrm{k}\right) \beta \mathrm{L}_{\mathrm{t}} / 2.6+ \\
\left(1-\mathrm{h}_{\mathrm{g}} / \mathrm{h}_{\mathrm{c}} \mathrm{k}_{0}\right) \mathrm{h}_{\mathrm{c}} / 2.6
\end{array}\right]
$$

In the formula, $\mathrm{U}_{50 \%}$ is $50 \%$ impulse discharge voltage of insulator strings, $\mathrm{m} ; h_{g}$ is the average height of the lightning rod in terms of ground, $\mathrm{m} ; h_{c}$ is average height of conductor, $m ; \beta$ is Shunt coefficient of tower; $k$ is coupling coefficient between conductor and lightning rod; $k_{0}$ is geometric coupling coefficient between conductor and lightning rod; $\mathrm{R}_{i}$ is tower grounding resistance, $\Omega$.

The Counter trip rate $\mathrm{n}$ can be calculated by the following formula

$\mathrm{n}=\mathrm{N} \eta \mathrm{gP}$

In the formula, $\mathrm{N}$ is the annual number of lightning in total; $\eta$ is arc building rate; $g$ is hitting rate, A single wire in the mountains area is $1 / 3$; $\mathrm{P}$ is the probability of occurrence of lightning current that over the counter lightning withstand level, $\lg \mathrm{P}=-\mathrm{I} / 88$.

\subsection{Calculation of simulation}

For simulating line model, in this paper, using ATPEMTP electromagnetic transient software to build. According to the actual set of line parameter modified the lightning current amplitude, the insulator flashover voltage amplitude is obtained by simulation and then calculated the tower's protection level. Next, the line's counter trip rate could be acquired by formula calculation.

This paper selects a $110 \mathrm{kV}$ line (full length $7.9 \mathrm{kM}$, 79 base towers in total) as an example, by collecting and testing parameters of the line, using ATP-EMTP to build the line model, part of the model (5\#-10\#) diagram is shown in Figure 1.

The calculation is based on simulation model. The lightening protection level, line counter-tripping rate, as well as tower counter-tripping rate are calculated, shown in table 1. 


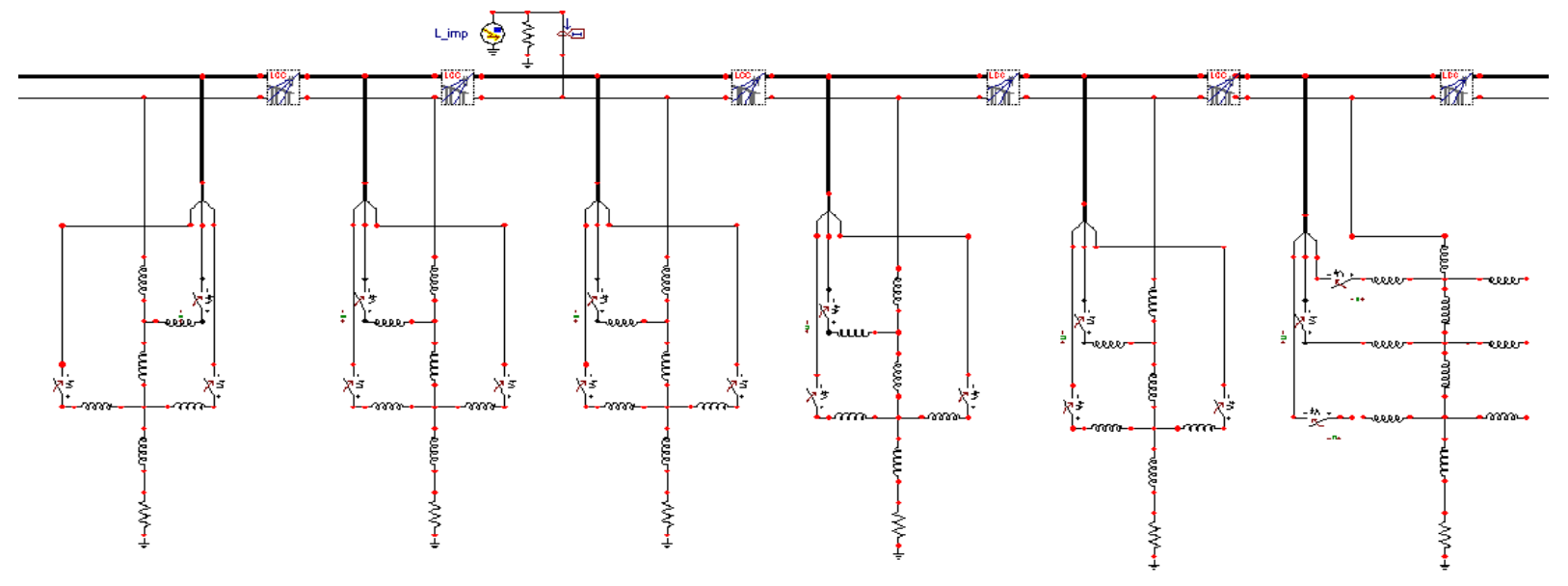

Fig.1 Part of simulation model

Table.1 Contrast of calculation result

\begin{tabular}{cccccccc}
\hline & Number of tower & $5 \#$ & $6 \#$ & $7 \#$ & $8 \#$ & $9 \#$ & $10 \#$ \\
\hline Lightning protection & Calculation of regulation & 73.37 & 68.04 & 68.61 & 63.48 & 67.74 & 80.38 \\
level(kA) & Calculation of simulation & 70 & 64 & 64 & 59 & 63 & 77 \\
\hline \multirow{2}{*}{ Counter trip rate } & Calculation of regulation & 0.978 & 1.258 & 1.305 & 1.642 & 1.301 & 0.747 \\
& Calculation of simulation & 1.068 & 1.398 & 1.472 & 1.846 & 1.473 & 0.816 \\
\hline
\end{tabular}

\subsection{Error Analysis}

Based on analysis of Table 1, it can be concluded that obtained counter-tripping rate have some errors between the simulation and regulation calculation. The specific reason is lumped inductance model of tower structures instead of considering the cross arm, when applied simulation analysis. However, the inductance is not considered during the regulation calculation. Besides, the regulation method is using a simple way to calculate the arc rate and stroke rate, which will have certain errors compared with actual situation. In addition, the simulation calculation is used without considering the corona effect between the wire and lightning conductor. Therefore, the entire calculation process is lack of insulator string voltage amplitude, when lightning strikes tower. Meanwhile, the lightning protection level of tower will increase. Such conditions will cause errors in the two calculation results.

\section{THE INFLUENCE OF COUNTER TRIP RATE BY SUBJECT VARIABLE}

From the formula (1), (2), there are many factors are affecting tower's counterattack trip rate, one of important reasons is protection level of tower. However, the protection level is also affected by many factors, for example: insulator string 50\% discharge voltage, line tower grounding resistance, shunt coefficient and coupling coefficient, etc. So analysis of the variables on the impact of the degree could select the most effective measures to reduce line counter trip rate. But lines are located in a mountainous area, the replacement of the tower or rebuild line to reduce the strike counter trip rate is obviously unreasonable. So only four factors can be considered, such as $50 \%$ main impulse discharge voltage $\mathrm{U}_{50 \%}$, line tower grounding resistance $\mathrm{R}_{i}$, shunt coefficient $\beta$ and coupling coefficient of insulator $k_{0}$. The main factor on the $50 \%$ impulse flashover voltage of the insulator string is type and the number of the insulator string; the line tower grounding resistance value is mainly affected by the grounding area, materials, size and other factors; the tower's shunt coefficient is mainly decided by the of surge arrester and lightning line installation; and setting up the coupling ground wire can increase the coupling coefficient of the tower. Based on the analysis of above variables, it can be seen that the impact of various factors on the counter trip rate of transmission line is affected by various factors, from MATLAB simulation, diagrams of variables which have influence on the transmission line counter trip rate can be obtained.

Selecting the $110 \mathrm{JJ}_{1}$ triangle angle iron of the line's parameters as the parameters during simulation, the height of the cross arm relative to the ground $h_{a}=21 \mathrm{~m}$, the height of tower $h_{t}=27.5 \mathrm{~m}$, the unit of inductance value set for simulation tower is $0.5 \mathrm{H} / \mathrm{m}$, so $\mathrm{L}_{t}=27.5 \times 0.5=13.75 \mu \mathrm{H}$, the conductor sag is $1.2 \mathrm{~m}$, the lightning conductor sag is $0.9 \mathrm{~m}$, so the average height of the transmission line $h_{c}=20.3 \mathrm{~m}$, the average height of the lightning rod is $h_{g}=27.2 \mathrm{~m}$. 


\subsection{The degree of transmission line's counter} tripping rate affected by tower grounding resistance and $50 \%$ impulse flashover voltage of insulator string

The $110 \mathrm{kV}$ transmission line has a single lightning line, that is, the tower's shunt coefficient $\beta$ is setting 0.9 . While, the line has not yet been coupled with the ground wire, so the coupling coefficient $\mathrm{k}=0.267$, the geometric coupling coefficient $k_{0}=0.214$, substituting values into the formula (1), (2):

$\mathrm{n}=8.64 \times 10^{-\mathrm{U}_{50 \%} / 88\left(0.65 \mathrm{R}_{\mathrm{i}}+7.93\right)}$

Comparing with 9 pieces and 8 pieces FC100P/146 insulator, FXBW (N) -110/100 composite insulator's $50 \%$ flashover voltage $\mathrm{U}_{50 \%}=832362 \mathrm{~V}$, $754544 \mathrm{~V}, 550000 \mathrm{~V}$. The simulation results are shown in the figure 2 .

From results, it can be seen that the tower grounding resistance has more influences on line counter trip rate's than $50 \%$ impulse flashover voltage of insulator string. The effect tends to be gentle when the grounding resistance is greater than $30 \Omega$ and flexible when resistance is less than $30 \Omega$. However, in terms of $50 \%$ flashover voltage of insulator string, the voltage amplitude is higher, the line counter-tripping rate is smaller. As the result, the line 's grounding resistance is required to be less than $30 \Omega$, the tower in the areas of high soil resistivity need to increase the number of insulators.

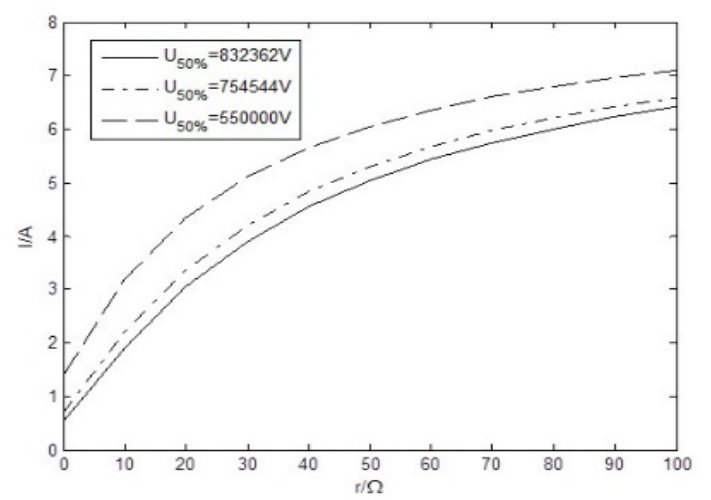

Fig. 2 Contrast of the impact of impulse grounding resistance and $50 \%$ flashover voltage on trip rate of Counterattack

\subsection{The degree of transmission line's counter trip rate affected by the tower grounding resistance and shunt coefficient}

Fixed tower number of insulators, selecting 8 pieces of $\mathrm{FC}-100 \mathrm{P} / 146$ insulator, $\mathrm{U}_{50 \%}=754544 \mathrm{~V}$, other factors is unchanged, substituting such factors into the formula (1), (2).

$$
\mathrm{n}=8.64 \times 10^{-550000 / 88\left(0.73 \times \beta \times \mathrm{R}_{\mathrm{i}}+2.62 \beta+5.57\right)}
$$

The simulation results are shown in the figure 4 , $110 \mathrm{kV}$ single lightening line and double lightening tower have different shunt coefficient: $\beta=0.9,0.86$. In addition, by the measure of setting up more arresters could reduce tower shunt coefficient.

Figure 3 also shows that the impulse grounding resistance less than $30 \Omega$ have a decisive role for counterattack trip rate. But more than $30 \Omega$, impacts will gradually reduce, at this time, the influence of the shunt coefficient on the counter trip rate being gradually increased. So the DL620-1997 rules that $110 \mathrm{kV}$ and above lines in mountain area, has to set up double lightning rod. For the line has high counter-tripping rate, it is supposed to be installed lightning arrester.

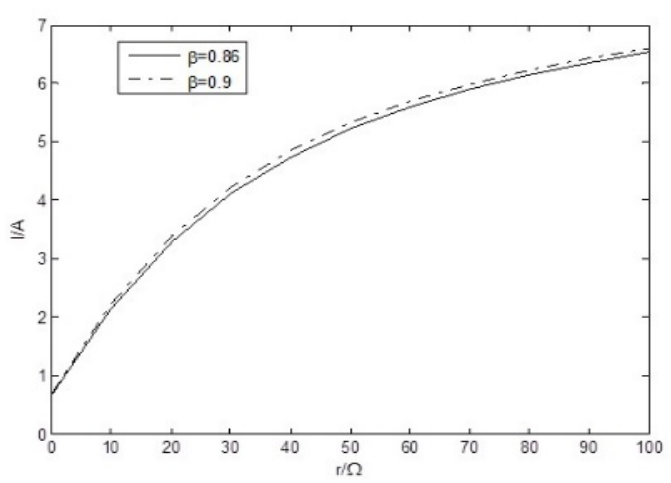

Fig.3 Contrast of the impact of impulse grounding resistance and shunting coefficient on counterattack trip rate

In addition, based on the figure 4 , the influence on counter-tripping rate caused by ground resistance $\mathrm{R}_{i}$ and coupling coefficient $\mathrm{k}$, it is basically the same as above. Thus, building coupling ground wire could larger coupling coefficient between the wire and the lightning conductor so that decrease the counter-tripping rate.

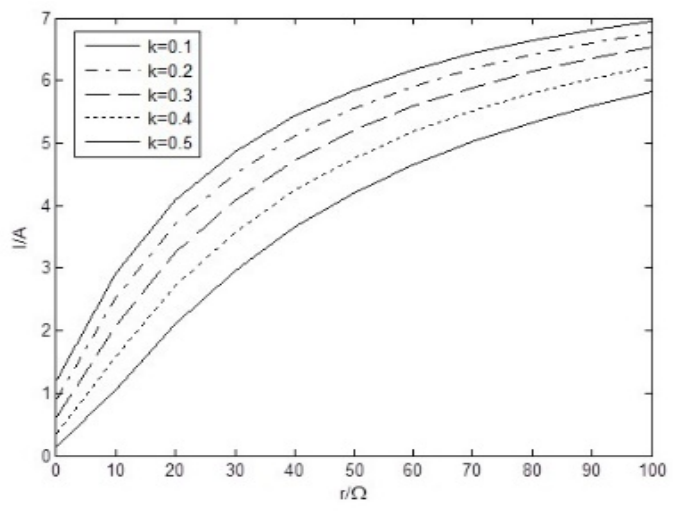

Fig.4 Impact on counter-tripping rate caused by impulse grounding resistance and coupling coefficient

From the above results, lightning protection on line requires the grounding resistance value lower than $30 \Omega$. For the tower with high counterattack trip rate, improving lightening protection level by adding insulators, setting lightning arrester or coupling ground wire etc. 


\section{CONCLUSION}

According to the comparison of regulation calculation and ATP-EMTP calculation for the simulation of transmission line trip rate, it is shown that using the electromagnetic transient software ATP-EMTP to achieve the simulation will acquire high accuracy on counter-tripping rate under the condition of choosing reasonable model and parameter. Finally, using MATLAB to simulate impact degree on counter-tripping rate by four variables: tower impulse grounding resistance, insulator on $50 \%$ impulse flashover voltage, lightning distribution coefficient of the tower as well as coupling coefficients. Consequently, determining the correct calculation results, which could be applied to the improvement concentrated on quantitative analysis of tower and line.

\section{REFERENCE:}

GAO Xin-zhi, QIU Wei, HAN Ai-zhi,et al. Study on the lightning protection problem of $35 \mathrm{kV}$ transmission and distribution line [J]. High Voltage Apparatus,2010,46(4):69-73.

HUANG Wei-chao, HE Jun -jia, LU Jia -zheng,etal.Calculation of lightning trip-out rate of trans missionlines under real lightning stroke distribution[J]. High VoltageEngineering, 2008, 34(7):1368-1372.

ZHENG Jiang, PENG Yu-tao,LE Gui-xian. Application of line surge arrester to lightning protection on the 60\# pole of 110 $\mathrm{kV}$ Li -Mao transmission line. Insulators and Surge Arresters, 2009(2): 27-32. 